\title{
BMJ Open Qualitative meta-synthesis of barriers and facilitators that influence the implementation of community pharmacy services: perspectives of patients, nurses and general medical practitioners
}

Lutfun N Hossain, ${ }^{1}$ Fernando Fernandez-Llimos, ${ }^{2}$ Tim Luckett, Joanna C Moullin, ${ }^{3}$ Desire Durks, ${ }^{1}$ Lucia Franco-Trigo, ${ }^{1}$ Shalom I Benrimoj, ${ }^{1}$ Daniel Sabater-Hernández ${ }^{1,4}$

To cite: Hossain LN, FernandezLlimos F, Luckett T, et al. Qualitative meta-synthesis of barriers and facilitators that influence the implementation of community pharmacy services: perspectives of patients, nurses and general medical practitioners. BMJ Open 2017;7:e015471. doi:10.1136/ bmjopen-2016-015471

- Prepublication history and additional material for this paper are available online. To view these files please visit the journal online (http://dx.doi. org/10.1136/bmjopen-2016015471).

75th International

Pharmaceutical Federation(FIP) World Congress of Pharmacy and Pharmaceutical Sciences; 29 September-30ctober, 2015; Dusseldorf, Germany

Received 8 December 2016 Revised 13 July 2017 Accepted 31 July 2017

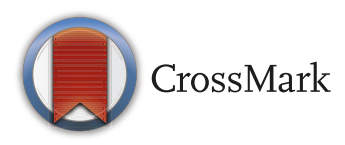

For numbered affiliations see end of article.

\section{Correspondence to}

Dr Daniel Sabater-Hernández; Daniel.SabaterHernandez@uts. edu.au

\section{ABSTRACT}

Objectives The integration of community pharmacy services (CPSs) into primary care practice can be enhanced by assessing (and further addressing) the elements that enable (ie, facilitators) or hinder (ie, barriers) the implementation of such CPSs. These elements have been widely researched from the perspective of pharmacists but not from the perspectives of other stakeholders who can interact with and influence the implementation of CPSs. The aim of this study was to synthesise the literature on patients', general practitioners' (GPs) and nurses' perspectives of CPSs to identify barriers and facilitators to their implementation in Australia.

Methods A meta-synthesis of qualitative studies was performed. A systematic search in PubMed, Scopus and Informit was conducted to identify studies that explored patients', GPs' or nurses' views about CPSs in Australia. Thematic synthesis was performed to identify elements influencing CPS implementation, which were further classified using an ecological approach.

Results Twenty-nine articles were included in the review, addressing 63 elements influencing CPS implementation. Elements were identified as a barrier, facilitator or both and were related to four ecological levels: individual patient $(n=14)$, interpersonal $(n=24)$, organisational $(n=16)$ and community and healthcare system $(n=9)$. It was found that patients, nurses and GPs identified elements reported in previous pharmacist-informed studies, such as pharmacist's training/education or financial remuneration, but also new elements, such as patients' capability to follow service's procedures, the relationships between GP and pharmacy professional bodies or the availability of multidisciplinary training/education.

Conclusions Patients, GPs and nurses can describe a large number of elements influencing CPS implementation. These elements can be combined with previous findings in pharmacists-informed studies to produce a comprehensive framework to assess barriers and facilitators to CPS implementation. This framework can be used by pharmacy
Strengths and limitations of this study

- The particular method chosen for this review (ie, qualitative meta-synthesis) is aimed at synthesising qualitative literature and so enabled a rich description of the barriers and facilitators perceived by GPS, patients and nurses who can influence the implementation of CPSs in Australia.

- A systematic search was conducted in three comprehensive electronic databases (ie, PubMed, Scopus and Informit), one of which (ie, Informit) is particularly relevant to the specific context where the results will be applied.

$>$

- A set of quality appraisal criteria was used to appraise all the studies included in this review to ensure minimal quality.

- Qualitative meta-synthesis was conducted by one researcher according to a three-stage method for thematic synthesis.

- This review was restricted to a specific implementation context (ie, Australia), to which its results are directly relevant and will be immediately applied and actions will be taken.

service planners and policy makers to improve the analysis of the contexts in which CPSs are implemented.

\section{INTRODUCTION}

The implementation of new health interventions and services into established healthcare practices and systems has been found to be challenging. ${ }^{1-4}$ The inherent complexity of both health services and healthcare systems may be fundamental to the implementation problem. ${ }^{5}$ According to current health planning approaches, the implementation 
of health services can be enhanced by comprehensively assessing the context in which they will be delivered. Analysis of the context should consider the stakeholders who can influence or be affected by the health service, as well as the social, physical, economic and policy environments that can enable or hinder the normalisation of the service. ${ }^{2} 7$ Early identification of these elements (including how they relate to or interact with each other) is a key step for developing suitable strategies and interventions to enhance health service implementation.

In the implementation science literature, several terms are used to refer to the elements that can influence service implementation and practice change. Some generally known examples, which are commonly used interchangeably in the literature, ${ }^{8}$ are: barriers and facilitators, ${ }^{9}$ determinants of practice, ${ }^{7}$ implementation factors ${ }^{10}$ or constructs. ${ }^{2}$ The current use of these terms encloses different concepts. For the purpose of this review and to avoid the terminological debate, we have used the term 'influential element' as a neutral term.

Amid increasing awareness of the uniqueness of the community pharmacy setting and the positive contribution pharmacists can make to healthcare, ${ }^{11}$ there has been a shift towards pharmacists providing more professional, patient-centred services. However, the implementation and sustainability of community pharmacy services (CPSs) and the integration of community pharmacists into primary healthcare teams remain a challenge worldwide. ${ }^{12}$ In consistence with this international trend, Australian community pharmacies are eager to provide CPSs and receive remuneration from the government for its provision but are experiencing challenges in the implementation, uptake and sustainability of CPSs. ${ }^{14}$ Extensive research has been conducted to identify the elements that from the perspective of community pharmacists (ie, service provider) can influence the implementation of CPSs. ${ }^{14-16}$ However, considering the view of a single stakeholder group is insufficient to comprehensively analyse the complexity of a particular implementation context. These limited analyses can lead to the development of inadequate implementation strategies and interventions. Patients, general practitioners (GPs) and primary care nurses are key stakeholders who interact with or are affected by CPSs and may be able to strongly influence the implementation of such services. These stakeholders may have their own particular views about CPSs and so can complement the findings from previous pharmacy-informed research. ${ }^{1415}$ Patients', nurses' and GPs' views and experiences regarding CPSs have been explored in several qualitative studies, ${ }^{17-21}$ but no review that collates and analyses such information exists. Qualitative meta-synthesis aims to synthesise qualitative literature to provide a new, more comprehensive interpretation of the findings that goes beyond the depth and breadth of the original studies and to broaden the range of concepts identified. ${ }^{22}{ }^{23}$ Thus, the aim of this study was to synthesise such qualitative literature to describe the broad range of elements that, from the patients', GPs' and nurses' perspectives, can hinder or enable the implementation of CPSs in Australia.

\section{METHODS}

\section{Search strategy, screening and eligibility criteria}

A systematic search was conducted in May 2015 in three electronic databases (ie, PubMed, Scopus and Informit), without time limits, to identify qualitative studies addressing patients', nurses' or GPs' views about CPSs in Australia. A CPS was assumed to refer to an action or set of actions delivered in or organised by a community pharmacy to optimise the process of care, with the aim of improving health outcomes and the value of healthcare. ${ }^{24}$ For the purpose of this review, CPSs are specific health programmes that are implemented in addition to routine professional activities performed by community pharmacists, which do not require any specific or extra implementation effort (ie, they are part of normal community pharmacy practice). Since medicine dispensing is the main routine activity in the community pharmacy, it was not considered as a CPS so it was excluded. Articles that did not address a specific CPS but interprofessional collaboration (ie, between community pharmacists and other healthcare professionals) were included as they can also provide insight into the elements influencing the implementation of CPSs. Full search strategies are available on online supplementary appendix 1 . In addition, the references from the included papers were searched manually for additional relevant studies. A two-step process was performed by one researcher to select studies for the analysis. As a first step, titles and abstracts were screened to identify and exclude non-relevant literature. In the second step, full texts of the remaining articles were reviewed to exclude those that: (1) were not related to CPSs; (2) did not address patient, nurse and/or GP perspective; (3) did not use qualitative research method$\mathrm{ology}^{25}$; (4) did not clearly identify the stakeholder (ie, patient, nurse or GP) as the source of the information; and (5) were not accessible in any of the research team university libraries or unattainable following contact with the authors.

All the included articles were checked by the same researcher for 'elementary quality assessment' using the first three criteria delineated by Dixon-Woods $e t a l^{26}$ to appraise qualitative research: (1) was the research question clear?; (2) was the research questions suited to qualitative inquiry?; and (3) were (A) sampling, (B) data collection and (C) analysis clearly described? Articles were excluded when no answer, or an unclear answer, was given to at least one of the three questions.

\section{Synthesis}

Qualitative meta-synthesis was conducted by one researcher according to the three-stage method for thematic synthesis described by Thomas $e t a l .^{27}$ The first stage of the analysis involved free line-by-line coding of the original data (study participants' quotes) and the 
Table 1 Levels where elements that can influence the implementation of community pharmacy services can exist (adapted from McLeroy et $a^{28}$ )

\begin{tabular}{ll}
\hline $\begin{array}{l}\text { Individual } \\
\text { patient }\end{array}$ & $\begin{array}{l}\text { Influential elements related to the personal characteristics and ideas concerning individual patients (ie, } \\
\text { individual determinants), such as their knowledge, beliefs and skills, that can affect their utilisation of } \\
\text { community pharmacy services. }\end{array}$ \\
Interpersonal & $\begin{array}{l}\text { Influential elements related to the healthcare providers and non-healthcare personnel (ie, individual } \\
\text { determinants) who are involved with the community pharmacy service and with whom patients associate (eg, } \\
\text { family, friends, pharmacists, pharmacy assistants, GPs and nurses) and the formal and informal relationships } \\
\text { between patients and healthcare professionals and healthcare professionals with other healthcare } \\
\text { professionals. }\end{array}$ \\
Organisational & $\begin{array}{l}\text { Influential elements related to characteristics of the community pharmacy setting and their decision } \\
\text { processes, and attributes of the community pharmacy service that can influence the success of }\end{array}$ \\
implementation.
\end{tabular}

study authors' interpretation of the original data. The process of coding involves summarising text from the results and discussion sections of each article into one or more descriptive issues (ie, codes) to capture meaning. The second stage of the process involved grouping codes into one or more descriptive themes. Subsequent articles were coded into pre-existing themes, and new themes were created when considered necessary. To simplify the terminology throughout this article, themes were interpreted as elements (ie, influential elements) that could positively (ie, facilitators) or negatively (ie, barriers) influence CPS implementation or practice change. A barrier was defined as 'any type of obstacle (material or immaterial) which can impede the dissemination, implementation and/or sustainability of a CPS', while a facilitator was defined as ' any type of element (material or immaterial) which can help to overcome barriers and/or accelerate the dissemination or implementation' of a CPS. ${ }^{16}$ Themes that were related to similar issues were further grouped to create one broad barrier or facilitator. The identified influential elements were reviewed by a second researcher to assess clarity, consistency and understanding. At the third stage, barriers and facilitators were organised using an adapted version of the Ecological Model (table 1), ${ }^{28}$ which classified them into four different levels: patient, interpersonal, organisational and community/system. The four levels defined in table 1 were used as an overarching structure, with further subheadings created during analysis, for appropriate allocation and organisation of the influential elements into the levels. The ecological model has been widely and successfully used for planning services in a variety of settings, targeting different populations and problems. ${ }^{29}{ }^{30}$ Coding of papers that were identified manually was conducted last. NVivo V.10 software (QSR International Pty; Doncaster, Victoria, Australia) was used to help manage and analyse the data. Once all the influential elements were identified, a second round of analysis was conducted to identify where a connection or relationship was mentioned between two or more elements.
Again, both study participants' quotes and study authors' data interpretation were reviewed for this purpose. A network representing the identified relationships was generated using a ForceAtlas2 layout ${ }^{31}$ with Gephi V.0.8. This article has been written following existing guidelines for reporting the synthesis of qualitative research (the Enhancing transparency in reporting the synthesis of qualitative research: ENTREQ Statement). ${ }^{32}$

\section{RESULTS}

The systematic and manual search identified 243 articles once duplicates were removed. After title and abstract screening, 124 full-text articles were assessed for eligibility of which 29 articles were included in the qualitative meta-synthesis (all of them fulfilled the appraisal criteria) (figure 1). A description of the papers included in the review can be found in table 2 . Of the 29 included papers, 15 addressed patients' perspectives only, 2 addressed nurses' perspectives only, 6 addressed GPs' perspectives only, 2 addressed nurses' and GPs' perspectives together, 3 addressed patients' and GPs' perspectives together and 1 addressed the views of all three participants. Twenty-three articles were related to a specific CPS, two were related specifically to interprofessional collaboration, three were related to both CPSs and interprofessional collaboration and one addressed concordance-based healthcare. The articles employed semistructured interviews $(n=23)$ and/ or focus groups $(n=11)$ as methods of data collection.

During the first stage of data extraction, 181 patient, 30 nurse and 91 GP codes were created. At the completion of the coding process, 63 influential elements were identified (table 3 ). These elements were found to exist as a barrier, facilitator or both. In several studies patients, nurses and GPs were able to describe approaches or strategies to overcome specific barriers. ${ }^{17-20} 33-43$ These strategies have been reported in table 3 as additional facilitators (marked with an asterisk). During coding of the manually identified papers, it seemed that conceptual 


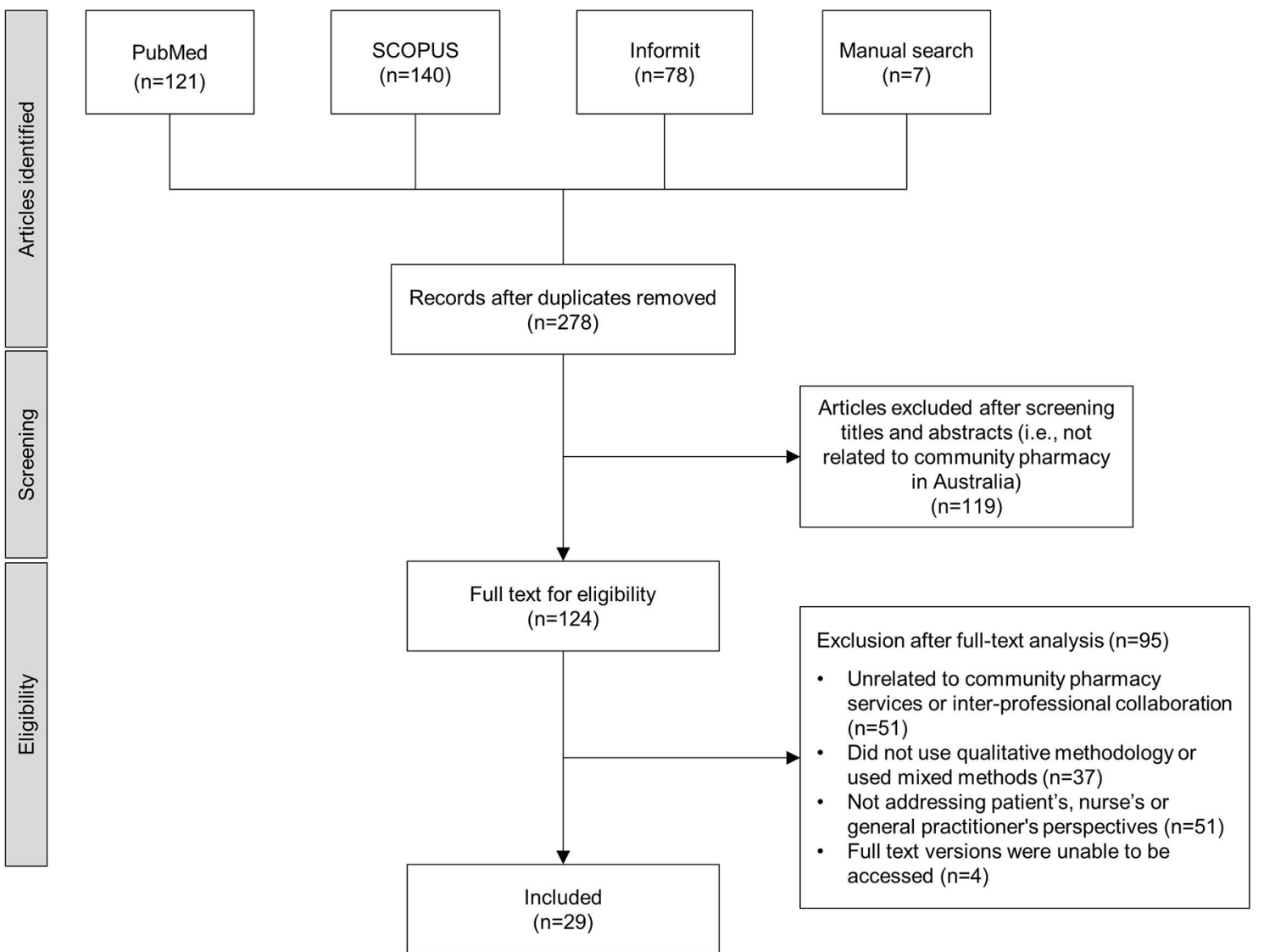

Figure 1 PRISMA flow diagram. PRISMA, Preferred Reporting Items for Systematic Review and Meta-Analysis.

saturation may have been reached, since no new barriers or facilitators were identified.

\section{Individual patient level}

All the 16 elements at the patient level were identified by patients. GPs and nurses did not identify any additional patient-related barriers and facilitators. Influential elements at this level were related to the patients' needs, preferences, perceptions and expectations, capabilities or previous experiences with community pharmacists and services. Patients' health-related concerns, understanding or perception of their health problems are important elements that influence patients' need for healthcare and so their decisions to use CPSs. Most patients held positive views about CPSs and the role of the pharmacist in providing such services. ${ }^{3840} 44$ Some articles highlighted that positive experiences were related to the patient feeling comfortable and welcomed in the pharmacy. ${ }^{44-46}$ When CPSs required a formal referral from the GP, some patients deterred from requesting the services. These patients perceived that by requesting a CPS they would be bothering the $\mathrm{GP}^{36}$ or offending and compromising their relationship with the GP. ${ }^{18}{ }^{40}{ }^{47}$ Patients also reported that having a negative experience with a CPS also deterred them from accessing and using such CPSs in the future. ${ }^{46}$

\section{Interpersonal level}

Influential elements at the interpersonal level were related to two categories or sublevels: (1) individual healthcare professionals (which also includes professional pharmacy staff) and (2) relationships (or interactions) between individuals (which includes both the relationships between healthcare professionals and between those professionals and patients).

\section{Individual healthcare professionals}

Seven elements were identified and related to characteristics of the community pharmacists $(n=4)$, nurses $(n=4)$ and GPs $(n=4)$ and characteristics of non-provider personnel (ie, other community pharmacy staff members, eg, pharmacy assistant $)(n=5)$. Articles reported that GPs' and nurses' service support varied depending on their perceptions or understanding of CPSs and the role of pharmacists. Home medicine review services had a great deal of approval and support from the GP perspective. ${ }^{40} 42$ On the other side, pharmacists providing immunisations raised some conflicting views among GPs since they believed this was the role of the GP or nurse practitioner. ${ }^{42}$ Some studies highlighted that GPs had a limited understanding of the capabilities of the pharmacist as service providers with pharmacists perceived as drug sellers in a retail environment. ${ }^{34-36} 4849$ Both patients and GPs implied the need for pharmacists to undergo upskilling and training to be qualified to provide some CPSs. ${ }^{34} 3747$

Relationships (or interactions) between individuals

Articles reported that well-established relationships between the pharmacist and the nurse or the GP, 


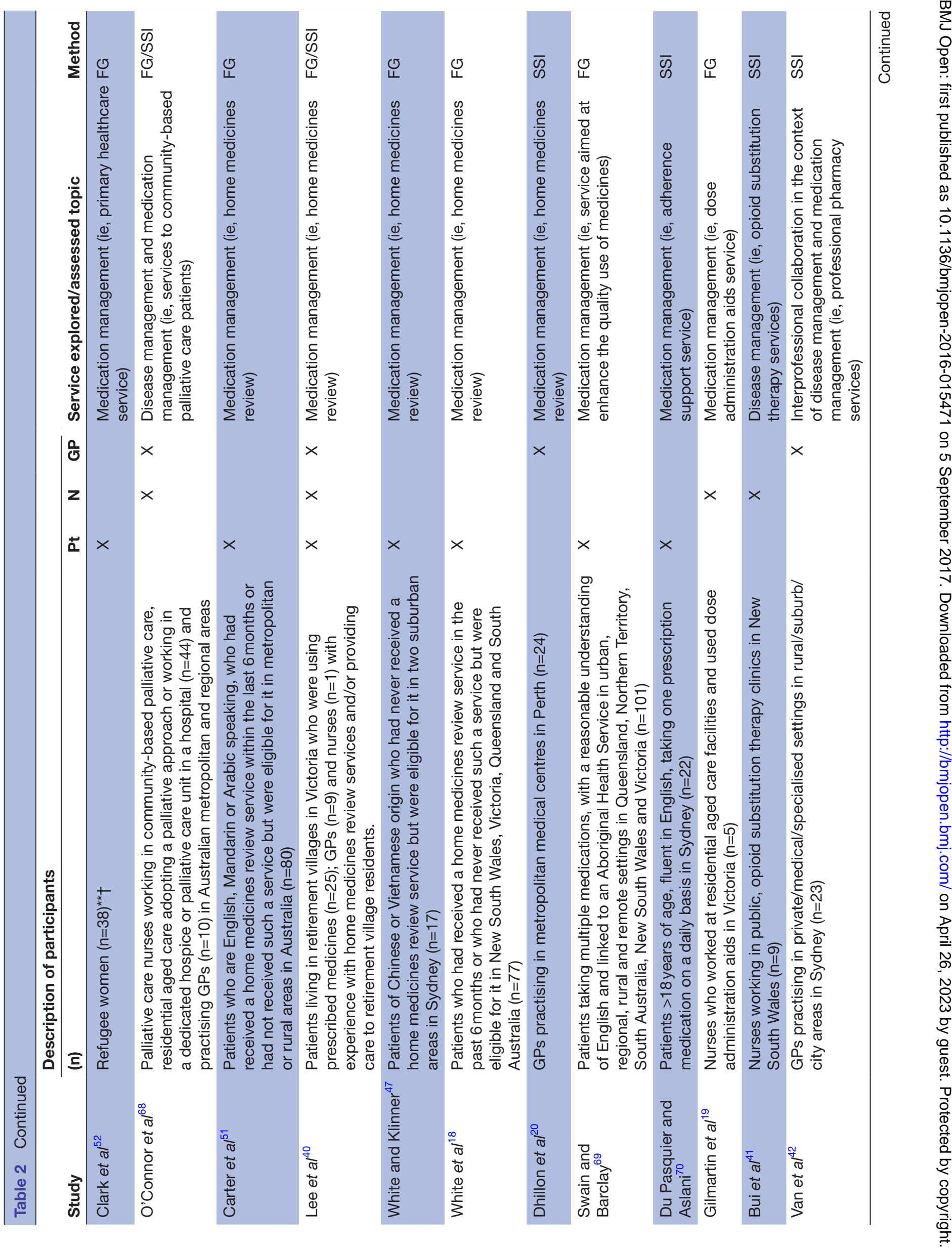




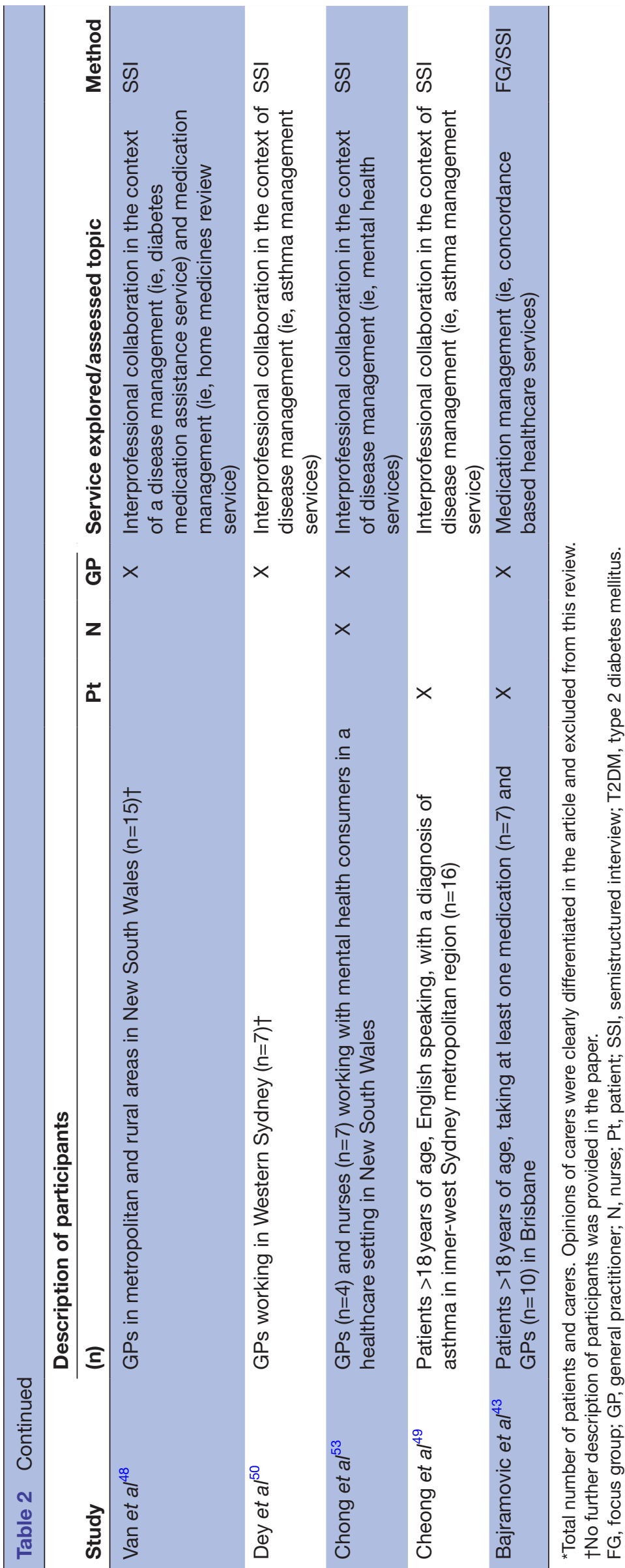


Table 3 Elements that can hinder (ie, barrier) or enable (ie, facilitator) the implementation of CPSs as identified by patients, general practitioners and nurses

\section{Effect on implementation and source of information (ie, stakeholder)}

Barrier* Facilitator ${ }^{*}$

Elements at the individual patient level

1. Patients' real or perceived need for healthcare (according to patients' individual concerns, understanding or perception of their health problems).

\section{Patients' awareness of the availability of CPS}

3. Patient personal desire or preference for CPSs

4. Patients' understanding, perceptions and expectations of their own role in $\mathrm{Pt}^{364970} \quad \mathrm{Pt}^{173649}$ the CPS

5. Patients' understanding, perceptions and expectations of the role of community pharmacists in healthcare
$\mathrm{Pt}^{1840495153} ; \mathrm{GP}^{17} \quad \mathrm{Pt}^{183335363843474951} ; \mathrm{N}^{41}$ $\mathrm{GP}^{17}$

$\mathrm{Pt}^{33} 40$ 47; $\mathrm{GP}^{20} 40$

$$
\mathrm{Pt}^{38474951}
$$

$\mathrm{Pt}^{17183536384649} ; \quad \mathrm{Pt}^{35384546496770}$

$\mathrm{N}^{41} ; \mathrm{GP}^{20}$

6. Patients' understanding, perceptions and expectations of the role of the GP Pt 3536404749516970 associated to the CPS

7. Patients' understanding, perceptions and expectations of collaboration $\quad \mathrm{Pt}^{49} \quad \mathrm{Pt}^{49}$ between healthcare professionals
8. Patients' availability, time to participate in CPSs
$\mathrm{Pt}^{33} 44$
$\mathrm{Pt}^{44} 49$

9. Patients' previous/background experiences with CPSs and multidisciplinary $\mathrm{Pt}^{38} 404649$ care

\begin{tabular}{|c|c|c|}
\hline $\begin{array}{l}\text { 10. Patient abilities; that is, to follow the procedures of the CPS or to self- } \\
\text { manage their health problems }\end{array}$ & $\mathrm{Pt}^{44}{ }^{49} ; \mathrm{GP}^{36} 4250$ & $\mathrm{Pt}^{44} 4767$ \\
\hline 11. Patients' satisfaction with the delivered CPSs and multidisciplinary care & & $\mathrm{Pt}^{36} 44-4651 ; \mathrm{N}^{41}$ \\
\hline 12. Patients' motivation towards CPSs & $\mathrm{Pt}^{51}$ & $\mathrm{Pt}^{445167}$ \\
\hline 13. Patients' level of emotional intelligence; that is, ability to cope with & $\mathrm{Pt}^{44}$ & $\mathrm{Pt}^{44}$ \\
\hline
\end{tabular}
negative experiences.

14. Patients' language, communication and cultural issues $\quad \mathrm{Pt}^{4752} ; \mathrm{GP}^{20}$

Elements at interpersonal level

a. Individual healthcare professionals (sublevel)

\section{a.1. Community pharmacist}
15. Knowledge, expertise, clinical and non-clinical skills (eg, cultural competency) to adequately provide CPSs

\section{$\mathrm{Pt}^{46} ; \mathrm{GP}^{34} 42$ \\ $\mathrm{Pt}^{18^{*}, 20,38,40,41^{*}, 42,44,48}$ $\mathrm{GP}^{37} 50$}
16. Communication skills, including the capacity to speak other languages
17. Humanistic attributes (eg, being respectful, caring, non-judgemental, $\mathrm{Pt}^{4769} ; \mathrm{N}^{68}$
$\mathrm{Pt}^{1833353847676970}$
$\mathrm{Pt}^{44}$ $\mathrm{Pt}^{33} 3536383944-464951$ friendly, empathetic, supportive and approachable)

18. Willingness, interest and motivation to provide CPSs and/or participate in $\quad \mathrm{N}^{33414967}$; GP ${ }^{40} \quad \mathrm{Pt}^{35}$ multidisciplinary collaboration

\section{a.2. Other community pharmacy staff members (eg, pharmacy assistants)}

19. Technical knowledge (eg, about a product)

20. Communication skills

21. Humanistic attributes

22. Ability to work professionally (eg, uphold patient confidentiality)

23. Experience working in the pharmacy

a.3. $G P$

24. Understanding, perceptions and expectations of their individual role with $\mathrm{GP}^{4250}$ regard CPSs
25. Understanding, perceptions and expectations of pharmacist's capabilities and role in healthcare
$\mathrm{GP}^{34} 36424850$
$\mathrm{GP}^{17} 3436374350$

26. Awareness of the availability of CPS

27. Willingness, interest, motivation to collaborate with CPSs

$\mathrm{GP}^{20}$

$\mathrm{GP}^{20}$

$\mathrm{GP}^{20} 50$ 


\section{Effect on implementation and source of} information (ie, stakeholder)

\section{Barrier* Facilitator†}

\section{a.4. Nurse}

28. Understanding, perceptions and expectations of their individual role within, or in regards to, CPSs

29. Knowledge and skills to adequately participate in the delivery of CPS 30. Attitude towards other healthcare professionals and their roles

31. Willingness, interest and motivation to collaborate with CPSs b. Relationships (or interactions) between individuals (sublevel)

32. Influence of friends and family on patients utilising CPSs (ie, they may provide support, affect patient's adherence or patient's enthusiasm with CPSs)

\section{Previous relationship between the patient and the pharmacist and its} nature (eg, trusting relationship)

34. Collaborative relationships between the pharmacist and other healthcare providers (eg, GPs) and their nature

\section{Communication channels and modes between pharmacists and other} healthcare providers (eg, GPs)

36. Existence of referral mechanisms between healthcare professionals, including also those between pharmacy support staff and pharmacists (ie, care coordination and transition)

38. Availability of multidisciplinary education, training and meetings for

$\mathrm{N}^{19}$

$\mathrm{N}^{19} \quad \mathrm{~N}^{19 *}$

$\mathrm{N}^{19} \quad \mathrm{~N}^{19}$

$\mathrm{Pt}^{38} 4447 \quad \mathrm{Pt}^{17^{\star}, 35^{\star}, 41}$

$\mathrm{Pt}^{18} ; \mathrm{GP}^{20} \quad \mathrm{Pt}^{1833363844-4651} ; \mathrm{GP}^{42}$

$\mathrm{Pt}^{43} ; \mathrm{N}^{41}$

$\mathrm{GP}^{34} 4042434868$

$\mathrm{Pt}^{35}{ }^{49} ; \mathrm{N}^{1941} ; \mathrm{GP}^{17^{*}, 20,52-}$

$\mathrm{N}^{1968} ; \mathrm{GP}^{36425053} \quad \mathrm{Pt}^{171835} ; \mathrm{N}^{41} ; \mathrm{GP}^{17424850}$

$\mathrm{Pt}^{46} ; \mathrm{GP}^{3642} ; \mathrm{N}^{41} \quad \mathrm{Pt}^{3845} ; \mathrm{GP}^{17203637404250}$ $\mathrm{N}^{41}$

$\mathrm{GP}^{42} 43$

$\mathrm{Pt}^{52^{*}, 56^{*}} ; \mathrm{N}^{41} ; \mathrm{GP}^{17344248}$

\section{Elements at the organisational level}

\section{a. Community pharmacy setting (sublevel)}

39. Accessibility of the pharmacy setting (eg, convenient location, colocation, $\mathrm{Pt}^{1769} ; \mathrm{N}^{41} \quad \mathrm{Pt}^{17,33,35,37,38,40,41,56^{*}, 57}$; no appointments required and opening hours)

40. Structural characteristics of the pharmacy setting, that is, size, provision of counselling rooms, use of visual space for posters and child-friendly area

\section{Privacy of the setting, including the availability of a private consultation area and limited involvement of multiple staff members who would be aware of the patients' personal matters}

42. Availability of suitable material resources to support the service (eg, educational material for patients, medical devices, patient data management system and so on)

\section{Sufficient qualified staff to perform CPS}

44. Organisation of the pharmacist's workload and time to deliver CPSs

\section{Organisational commitment to implement a CPS}

46. Promotion of the CPS to facilitate its uptake

$$
\text { b. CPS }
$$

47. Extent to which the CPS meets and is tailored to fit individual patient's needs or fills existing gaps in healthcare practice (this enhances the value of the service for patients and healthcare professionals)

48. Quality of the CPS (eg, validity, accuracy of the materials and tools used, CPSs provided in a timely manner, provision of both verbal and written information, professional advice and education and so on)

$\begin{array}{ll}\mathrm{Pt}^{1769} ; \mathrm{N}^{41} & \mathrm{Pt}^{17,33,35,37,38,40,41,56^{*}, 57} ; \\ \mathrm{Pt}^{39} & \mathrm{~N}^{41} ; \mathrm{GP}^{40,41,47^{*}}, 52^{*}, 53\end{array}$

$\mathrm{Pt}^{183839464969} ; \quad \mathrm{Pt}^{394445}$ $\mathrm{GP}^{20} ; \mathrm{N}^{68}$

49. Complexity of the CPS for use by healthcare professionals

\begin{tabular}{|c|c|}
\hline $\mathrm{Pt}^{52} ; \mathrm{GP}^{20} 4043$ & $\mathrm{Pt}^{47}$ \\
\hline $\begin{array}{l}\mathrm{Pt}^{38474969} ; \mathrm{N}^{41} ; \\
\mathrm{GP}^{3340}\end{array}$ & $\mathrm{Pt}^{38} 43$ \\
\hline
\end{tabular}

$\mathrm{Pt}^{33}{ }^{38} ; \mathrm{N}^{41}$

$\mathrm{Pt}^{33^{*}, 35^{\star}, 47} ; \mathrm{GP}^{20}$

$\mathrm{Pt}^{18353640464951} ; \quad \mathrm{Pt}^{183335384045-47495169}$; $\mathrm{GP}^{4250} \quad \mathrm{~N}^{40} ; \mathrm{GP}^{2037404243485053}$

$\mathrm{Pt}^{51} ; \mathrm{GP}^{4043} ; \mathrm{N}^{19} \quad \mathrm{Pt}^{18384445} ; \mathrm{GP}^{20}$ $\mathrm{GP}^{20} ; \mathrm{N}^{1941}$ 


\section{Extent to which CPSs provide ongoing support, follow-up and feedback GP ${ }^{42}$} to patients

51. Flexibility to use different communication channels (eg, telephone and website) to interact with patients and healthcare providers

\section{Consistency in the community pharmacist delivering the CPS}

53. Involvement of other healthcare providers in delivering the CPS

\section{Costs and duration of the CPS consultation for the patient}

Elements at the community and health system level

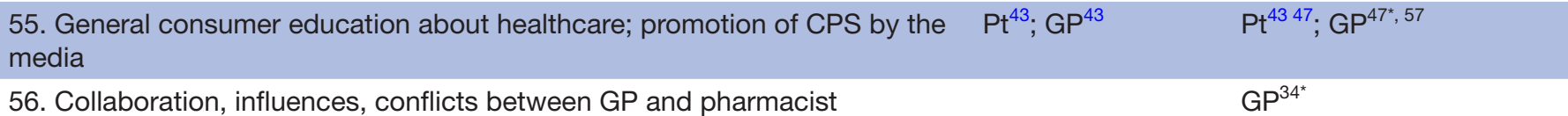
professional bodies

$\begin{array}{ll}\text { 57. Organisation of GPs' workload and time to collaborate with CPSs } & \text { GP }^{2040425053} \\ \text { 58. Complexity of system-level administrative processes (eg, tedious } & \text { GP }^{1720404348}\end{array}$
paperwork) associated to the delivery of CPS; that is, complying with the requirements of the department of health

\begin{tabular}{|c|c|c|}
\hline 59. Availability of an electronic system for sharing information & $\mathrm{Pt}^{18} 49$ & $\begin{array}{l}\mathrm{Pt}^{17^{*}, 57} ; \mathrm{N}^{19^{*}} ; \mathrm{GP}^{17,20^{*}, 36^{*}},\end{array}$ \\
\hline
\end{tabular}

60. Presence of agreed healthcare protocols, regulations, rules and policies to $\mathrm{Pt}^{52} ; \mathrm{N}^{41}$ facilitate the delivery of CPSs

$\begin{array}{ll}\text { 61. Limits on the healthcare budget; that is, funding allocated to support CPS } \quad \mathrm{GP}^{17404350} & \mathrm{Pt}^{44,56^{*}} ; \mathrm{GP}^{174243} \\ \text { delivery } & \mathrm{Pt}^{56^{*}} ; \mathrm{N}^{51^{*}}\end{array}$
professional collaboration

63. Organisation of the healthcare system $\quad \mathrm{Pt}^{49} ; \mathrm{GP}^{43}$

*Barrier: the element was mentioned to act as a BARRIER or hinder to the implementation of CPSs.

†Facilitator: the element was mentioned to act as a FACILITATOR or enabler to the implementation of CPSs.

$\left(^{\star}\right)$ This element was reported as a potential strategy to overcome a barrier (ie, facilitator).

CPSs, community pharmacy services; GP, general practitioner; N, nurse; Pt, patient.

including collaborative relationships, were essential for the success of a CPS. ${ }^{171920354150}$ Multidisciplinary education and training for healthcare professionals was suggested as a way to improve healthcare professional competence. ${ }^{49}$ Similarly, characteristics of the relationship between the patient and the pharmacist (eg, trust) was a key element that influenced pharmacy choice, contributed to the patient adhering to the CPS, and accepting the intervention. ${ }^{18} 33363844-4651$ Some articles reported the influence of family and friends on patient utilisation of CPSs (eg, providing support and influencing motivation), ${ }^{35}$ and others commented on the integration of partners into the CPS (eg, provision of group sessions with partners).$^{35} 45$

\section{Organisational level}

Also at the organisational level, influential elements were divided into two sublevels: (1) the community pharmacy setting $(\mathrm{n}=8)$ and $(2)$ the service itself $(\mathrm{n}=8)$.
The community pharmacy setting

Some articles identified the accessibility of the pharmacy facilitated interprofessional relationships between GPs and pharmacists ${ }^{42}$ and influenced patient ${ }^{1738} 45$ and nurse $^{41}$ participation in CPS. In some articles, non-English speaking patients reported that the lack of multilingual staff limited their awareness and access to CPSs. ${ }^{47} 52$ Other articles noted GP and nurse concerns regarding the lack of pharmacies that provide CPSs ${ }^{41}$ and insufficient accredited pharmacists to perform CPSs. ${ }^{40} 43$

\section{The community pharmacy service}

Concerns regarding the validity and accuracy of the tools and instruments used (eg, medical devices and medication charts) were raised by GPs and nurses. ${ }^{1942}$ Patients and nurses commented that having the same service provider at each encounter facilitated rapport building between the patient and the pharmacist ${ }^{38} 4551$ and caused fewer errors when it came to preparing dose administration aids. ${ }^{19}$ Furthermore, patients, nurses and GPs reported 
on the involvement/participation of healthcare professionals other than pharmacists in the provision of CPSs, ${ }^{38}$ or to act as a point of liaison, ${ }^{20}$ to improve the quality and efficiency of the service. The cost of the service was a key element, mentioned by all stakeholders, that could either discourage $^{4149}$ or motivate ${ }^{45}$ patients to use services. In particular, it was mentioned that smaller, manageable cost payments for patients could facilitate CPS use. ${ }^{41}$

\section{Community and healthcare system level}

Nine influential elements were identified at this level. Several articles identified the need for adequate remuneration for GPs and pharmacists for participating in and providing CPSs ${ }^{17425052}$ as well as the implementation of an electronic system of information sharing between these two healthcare professionals. ${ }^{19} 203643$ GPs also cited the availability of competing, government-funded health programmes and their high level of workload and lack of time as contributing to their low participation in $\mathrm{CPSs}^{40}{ }^{40}$ Where services were available, remunerated and widely supported by GPs and patients, such as home medicine reviews (ie, a medication review service), GPs mentioned complex bureaucratic procedures (eg, completing tedious documents) may discourage their use. ${ }^{17} 20404348$ Despite this, the home medicine review service was generally considered successful by GPs and a frequently reported reason for this was the presence of a clear protocol guiding service delivery. ${ }^{20} 4248$ GPs also suggested increased and improved collaboration between pharmacy and GP professional representative bodies may improve awareness of the services and encourage participation. The media was perceived to have an important role in improving awareness of and promoting CPSs. Finally, some broad comments suggesting some additional issues at the higher levels of the healthcare system were mentioned, such as 'better and more responsible organisation of the healthcare system' ${ }^{43}$

With regards to the interactions between the identified influential elements, 12 articles out of 29 mentioned some form of a relationship between certain elements. ${ }^{203341424446-4850515354}$ As shown in online supplementary appendix 2 , a total of 27 relationships between 25 elements were found, with 10 elements presenting two or more relationships with others (two elements showed five or more interactions). As a result of the limited, unsystematic information reported in the articles, a sparse network disclosing the recognised relationships between elements was obtained (see online supplementary appendix 2 ).

\section{DISCUSSION}

To the best of our knowledge, this is the first review that summarises comprehensive information on the elements that, according to patients, nurses and GPs, can enable or hinder the implementation of CPSs. Patients, GPs and nurses are key members of the primary healthcare team and their support and expectations for CPSs can highly influence their implementation. ${ }^{19} 42$ 54-57 Thus, by synthesising and organising the influential elements identified by these key stakeholders, this review can optimise future analyses of barriers and facilitators to the implementation of CPSs and so potentially enhance their integration into primary practice. Importantly, this work was intentionally restricted to a specific implementation context (ie, Australia), to which its results are directly relevant and will be immediately applied. Focusing only on Australia is not considered a limitation of the study, rather it is a sensible decision that allows knowledge about a particular context of interest to be gained. Including studies conducted in contexts or healthcare systems other than Australia (eg, UK, USA and so on), where barriers and facilitators to CPS implementation can be dissimilar in nature and expressed differently, may have brought irrelevant or inappropriate information to this analysis, and so hinder the understanding of the context of interest. However, it should be noted that Australia is a country with a large experience in CPS implementation and where significant research has been conducted in this regard compared with other countries worldwide. Therefore, it is expected that the comprehensive list of influential elements identified in this context may be relevant to start investigating barriers and facilitators to CPS implementation in countries with less experience. Furthermore, the elements identified in this review can provide insight to pharmacy service planners in other countries to guess and avoid some problems in the implementation of CPSs beforehand.

Barriers and facilitators to the implementation of CPSs in Australia have been well researched and reported from the perspective of community pharmacists. ${ }^{14} 155658$ In this regard, the results of this review confirms that patients, nurses and GPs also recognise some of the influential elements reported in previous pharmacist-informed studies, such as the pharmacist's education and training, collaboration between the pharmacist and the GP, accessibility of the pharmacy setting and financial remuneration. However, this study provides additional insight into further barriers and facilitators, across different ecological levels, that are relevant to other key stakeholders and so are less likely to be reported by pharmacists, for example, patients' capability to follow the procedures of the service, GPs' workload, nurses' attitudes towards other healthcare professionals/services, the actual relationships between GP and pharmacy professional bodies or the availability of multidisciplinary training and education. These results highlight the importance of engaging key stakeholders other than pharmacists to better understand the contexts in which CPSs are implemented. In other words, disregarding the input of these stakeholders (or considering only the views of pharmacists) may lead to an incomplete and biased understanding of the implementation context which, in turn, can result in service underutilisation, unsuccessful implementation and limited service impact. ${ }^{59}$ Generally, involving relevant stakeholders throughout the development, implementation and evaluation of health programmes is crucial 
to increase the chances of any of those initiatives being effective and successfully implemented. ${ }^{629} 3060$ Indeed, this is equally relevant to CPS planning. ${ }^{61} 62$

Semistructured interviews and/or focus group with healthcare professionals and patients appear to be appropriate methods to identify a large number of unique influential elements. ${ }^{63}$ Thus, pharmacy service planners can continue to use these methods to identify determinants of pharmacy practice in their own context. Although, the type of qualitative method used may affect the type of barriers/facilitators identified, it is more likely that the aims of the studies included in this review, their target population and/or the specific service/topic addressed by the study may have had a stronger influence in the type of barriers or facilitator identified.

The results of this review can assist pharmacy service planners and researchers to better identify the elements that may be enabling or hindering the implementation of existing CPSs. By combining the list of influential elements generated in this review with previous findings in pharmacists-informed studies, a comprehensive framework to assess barriers and facilitators to CPS implementation can be produced. Assessing and understanding the elements influencing pharmacy practice and service implementation must be a key early step in developing appropriate, multilevel programmes (ie, including interventions targeting elements at different levels) aimed at enhancing the integration of CPSs into the healthcare system. ${ }^{29} 306264$ Also, influential elements should be prompted and assessed when designing new CPSs. Identifying elements prior to designing a new CPS may guide both the early adaptation of the service to the context, as well as the early development of tailored implementation programmes to better fit (or change) the implementation context. As an analysis of influential elements is likely to yield a large number of items, it would not be feasible to address each and every one of those elements. Thus, once elements have been identified for a specific context, further efforts are required to prioritise those elements that are most relevant and can be practically addressed. ${ }^{85}$ In this regard, McMillan et $a l^{66}$ provide a summary of methods used to determine priorities and how they have been used in pharmacy practice research, which can guide pharmacy service planners in this regard.

The analysis conducted in this review revealed three concerns that must be considered to improve future studies aimed at identifying influential elements. On the one hand, some influential elements at the community and healthcare system level were too broadly described (ie, 'organisation of the health system') and further exploration is needed to clearly understand the specific 'items' that they encompass. Presumably, the list of determinants of practice described by Flottorp $e t a l^{7}$ (ie, Tailored Implementation in Chronic Disease checklist) can provide more detail regarding influential elements at the higher community and healthcare system level and so can initially assist to better frame future analysis of barriers and facilitators to CPS implementation.
Particularly, the determinants under the domains 'Incentives and resources', 'Capacity for organisational change' and 'Social political and legal factors' seem particularly relevant for this purpose. Importantly, to bring further insight on the elements at the community and healthcare system level, it would be important to include and explore the perspectives of other potential key stakeholders, such as other healthcare providers (eg, specialists), caregivers, representatives of healthcare organisations and professional bodies, policy makers and so on. Furthermore, future studies aimed at identifying barriers and facilitators to CPS implementation must better describe and understand the relationships between elements. ${ }^{2}$ This may help to understand how elements influence each other and which elements are more suitable to be addressed (based on the overall effect that they can produce on other elements) when designing implementation efforts.

\section{Limitations}

The network analysis intended in this study was strongly constrained by the limited and unsystematically reported information about the relationships between influential elements. As a result, it was decided not to report further results of the network analysis beyond its pictorial representation. The potential of a full network analysis should be considered in future studies aimed at analysing elements that influence the implementation of CPSs. A suitable network analysis can help to better understand the complex relationships between these elements, detect the core elements that may primarily explain the implementation challenge and provide insight on the key leverage points that should be targeted within the network to enhance service implementation. Ideally, accurate information on relevant attributes of the influential elements (and the interactions between them) should be collected by the authors of the primary studies to increase the potential of a network analysis, for example, the frequency of occurrence, the direction of the relationships, the domain or level where the element is located (ie, patients, healthcare professionals, professional interactions and so on), the relative relevance of each element or the effect on implementation outcomes (ie, performance as barrier or facilitator).

Following the particular method chosen for this review (ie, qualitative meta-synthesis), ${ }^{22}{ }^{23}$ only primary research articles that used qualitative methods were included. Meta-synthesis enabled a rich description of elements perceived by GPs, patients and nurses to influence implementation of CPSs in Australia. Future reviews that synthesise the quantitative literature on this topic are encouraged. Appraising qualitative research is controversial because of the difficulty of using information about quality to inform syntheses (eg, even studies with flaws in methodology can provide valuable information).$^{26}$ Furthermore, there is no gold standard on appraising qualitative studies. ${ }^{32}$ The elementary quality assessment conducted in the current review was aimed at ensuring minimal quality while identifying a broad 
range of elements that might influence CPS implementation. Lastly, the papers included in this review were not restricted by the time at which they were published, since the aim of the study was to include all relevant papers that can inform about any influential element that has been noted in practice. It is important to acknowledge that as contexts can change over time, the effect of influential elements can also change, cease to exist or new elements can emerge. It is therefore important to regularly monitor elements and prioritise those that must be addressed.

\section{CONCLUSION}

This qualitative meta-synthesis identified a broad range of elements that, according to patients, GPs and nurses, can enable (ie, facilitators) or hinder (ie, barriers) the implementation of CPSs. These influential elements are located at different ecological levels and should be considered together with those previously identified in pharmacy-informed studies to comprehensively analyse the barriers and facilitators to the implementation of CPSs. Future studies aimed at that purpose must involve multiple stakeholder groups (ie, others than only pharmacists) and better understand the relationships between influential elements to increase the usefulness and interest of their findings. Further to the identification of the influential elements, key stakeholders should keep involved in developing suitable, multilevel programmes aimed at enhancing CPS implementation.

\section{Author affiliations}

${ }^{1}$ Graduate School of Health, University of Technology, Sydney, New South Wales, Australia

${ }^{2}$ Department of Social Pharmacy, Faculty of Pharmacy, Research Institute for Medicines, University of Lisbon, Lisboa, Portugal

${ }^{3}$ Department of Psychiatry, University of California, San Diego, California, USA

${ }^{4}$ Academic Centre in Pharmaceutical Care, University of Granada, Granada, Spain

Acknowledgements We would like to acknowledge Antonio E Mendes (Universidade Federal do Parana, Brazil) for his collaboration in the network analysis.

Contributors Conception or design of the work: LNH, FF-L, TL and DS-H. Data collection: LNH, DD and LF-T. Data analysis and interpretation: LNH, JCM, CB and DS-H. Drafting the article: LNH, FF-L, TL and DS-H. Critical revision of the article: LNH, JCM, FF-L, TL and DS-H. Final approval of the version to be published: all authors.

Funding LNH was awarded a University of Technology Sydney (UTS) President's 424 Scholarship and a UTS Chancellors Research Scholarship. This work is part of a larger UTS Chancellor's Postdoctoral Research Fellowship awarded to Dr DSH (UTS ID number: 2013001605).

Competing interests None declared.

Provenance and peer review Not commissioned; externally peer reviewed.

Data sharing statement № additional data are available.

Open Access This is an Open Access article distributed in accordance with the Creative Commons Attribution Non Commercial (CC BY-NC 4.0) license, which permits others to distribute, remix, adapt, build upon this work non-commercially, and license their derivative works on different terms, provided the original work is properly cited and the use is non-commercial. See: http://creativecommons.org/ licenses/by-nc/4.0/

(C) Article author(s) (or their employer(s) unless otherwise stated in the text of the article) 2017. All rights reserved. No commercial use is permitted unless otherwise expressly granted.

\section{REFERENCES}

1. Chaudoir SR, Dugan AG, Barr CH. Measuring factors affecting implementation of health innovations: a systematic review of structural, organizational, provider, patient, and innovation level measures. Implement Sci 2013;8:22.

2. Damschroder LJ, Aron DC, Keith RE, et al. Fostering implementation of health services research findings into practice: a consolidated framework for advancing implementation science. Implement Sci 2009;4:50.

3. Haines A, Kuruvilla S, Borchert M. Bridging the implementation gap between knowledge and action for health. Bull World Health Organ 2004;82:724-31.

4. Grol R, Grimshaw J. From best evidence to best practice: effective implementation of change in patients' care. Lancet 2003;362:1225-30.

5. Plsek PE, Greenhalgh T. Complexity science: The challenge of complexity in health care. BMJ 2001;323:625-8.

6. Craig P, Dieppe P, Macintyre S, et al. Developing and evaluating complex interventions: the new Medical Research Council guidance. BMJ 2008;337:a1655.

7. Flottorp SA, Oxman AD, Krause J, et al. A checklist for identifying determinants of practice: a systematic review and synthesis of frameworks and taxonomies of factors that prevent or enable improvements in healthcare professional practice. Implement Sci 2013;8:35.

8. Baker R, Camosso-Stefinovic J, Gillies C, et al. Tailored interventions to address determinants of practice. Cochrane Database Syst Rev 2015;4:CD005470.

9. Gastelurrutia MA, Benrimoj SI, Castrillon CC, et al. Facilitators for practice change in Spanish community pharmacy. Pharm World Sci 2009;31:32-9.

10. Moullin JC, Sabater-Hernández D, Benrimoj SI. Model for the evaluation of implementation programs and professional pharmacy services. Res Social Adm Pharm 2016;12:515-22.

11. Sabater-Hernández D, Sabater-Galindo M, Fernandez-Llimos F, et al. A systematic review of evidence-based community pharmacy services aimed at the prevention of cardiovascular disease. J Manag Care Spec Pharm 2016;22:699-713.

12. Mossialos E, Courtin E, Naci H, et al. From "retailers" to health care providers: Transforming the role of community pharmacists in chronic disease management. Health Policy 2015;119:628-39.

13. Kaae S, Christensen ST. Exploring long term implementation of cognitive services in community pharmacies - a qualitative study. Pharm Pract 2012;10:151-8.

14. Berbatis C, Sunderland V, Joyce A, et al. Enhanced pharmacy services, barriers and facilitators in Australia's community pharmacies: Australia's National Pharmacy Database Project. Int $J$ Clin Pharm 2007;15:185-91.

15. Roberts AS, Benrimoj SI (Charlie), Chen TF, et al. Implementing cognitive services in community pharmacy: a review of facilitators used in practice change. Int J Pharm Pract 2006;14:163-70.

16. Gastelurrutia MA, Fernandez-Llimos F, Garcia-Delgado P, et al. Barriers and facilitators to the dissemination and implementation of cognitive services in Spanish community pharmacies. Seguim Farmacoter 2005;3:65-77.

17. Cvetkovski B, Armour C, Bosnic-Anticevich S. Asthma management in rural New South Wales: perceptions of health care professionals and people with asthma. Aust $J$ Rural Health 2009;17:195-200.

18. White L, Klinner C, Carter S. Consumer perspectives of the Australian Home Medicines Review Program: benefits and barriers. Res Social Adm Pharm 2012;8:4-16.

19. Gilmartin JF, Marriott JL, Hussainy SY. Exploring factors that contribute to dose administration aid incidents and identifying quality improvement strategies: the views of pharmacy and nursing staff. Int $J$ Pharm Pract 2014;22:407-14.

20. Dhillon AK, Hattingh HL, Stafford A, et al. General practitioners' perceptions on home medicines reviews: a qualitative analysis. BMC Fam Pract 2015;16:16:16.

21. Rayes IK, Abduelkarem AR. A qualitative study exploring physicians' perceptions on the role of community pharmacists in Dubai. Pharm Pract 2016;14:738.

22. Mohammed MA, Moles RJ, Chen TF. Meta-synthesis of qualitative research: the challenges and opportunities. Int J Clin Pharm 2016;38:695-704.

23. Walsh D, Downe S. Meta-synthesis method for qualitative research: a literature review. J Adv Nurs 2005;50:204-11.

24. Moullin JC, Sabater-Hernández D, Fernandez-Llimos F, et al. Defining professional pharmacy services in community pharmacy. Res Social Adm Pharm 2013;9:989-95.

25. Hennink MM, Hutter I, Bailey A. Qualitative research methods. Los Angeles, Calif, London: SAGE, 2011. 
26. Dixon-Woods M, Shaw RL, Agarwal S, et al. The problem of appraising qualitative research. Qual Saf Health Care 2004;13:223-5.

27. Thomas J, Harden A. Methods for the thematic synthesis of qualitative research in systematic reviews. BMC Med Res Methodol 2008;8:1-10.

28. McLeroy KR, Bibeau D, Steckler A, et al. An ecological perspective on health promotion programs. Health Educ Q 1988;15:351-77.

29. Bartholomew LK, Markham CM, Ruiter RAC, et al. Planning health promotion programs: An Intervention Mapping approach. 4th ed. San Francisco, CA: Jossey-Bass, 2016.

30. Green LW, Kreuter MW. Health program planning: An educational and ecological approach. 4th ed. Boston: McGraw-Hill, 2005.

31. Jacomy M, Venturini T, Heymann S, et al. ForceAtlas2, a continuous graph layout algorithm for handy network visualization designed for the Gephi software. PLoS One 2014;9:e98679.

32. Tong A, Flemming $\mathrm{K}$, Mclnnes $\mathrm{E}$, et al. Enhancing transparency in reporting the synthesis of qualitative research: ENTREQ. BMC Med Res Methodol 2012;12:181.

33. McMillan SS, Sav A, Kelly F, et al. How to attract them and keep them: the pharmacy attributes that matter to Australian residents with chronic conditions. Int J Pharm Pract 2014;22:238-45.

34. Rieck A, Pettigrew S. How physician and community pharmacist perceptions of the community pharmacist role in Australian primary care influence the quality of collaborative chronic disease management. Qual Prim Care 2013;21:105-11.

35. Barbara S, Krass I. Self management of type 2 diabetes by Maltese immigrants in Australia: can community pharmacies play a supporting role? Int J Pharm Pract 2013;21:305-13.

36. Bereznicki B, Peterson G, Jackson S, et al. Perceived feasibility of a community pharmacy-based asthma intervention: a qualitative follow-up study. J Clin Pharm Ther 2011;36:348-55.

37. Um IS, Armour C, Krass I, et al. Weight management in community pharmacy: what do the experts think? Int J Clin Pharm 2013;35:447-54.

38. Maher JH, Hughes $\mathrm{R}$, Anderson $\mathrm{C}$, et al. An exploratory investigation amongst Australian mothers regarding pharmacies and opportunities for nutrition promotion. Health Educ Res 2013;28:1040-50.

39. Hattingh HL, Knox K, Fejzic J, et al. Privacy and confidentiality: perspectives of mental health consumers and carers in pharmacy settings. Int J Pharm Pract 2015;23:52-60.

40. Lee CY, George J, Elliott RA, et al. Exploring stakeholder perspectives on medication review services for older residents in retirement villages. Int J Pharm Pract 2012;20:249-58.

41. Bui J, Day C, Hanrahan J, et al. Senior nurses' perspectives on the transfer of opioid substitution treatment clients from clinics to community pharmacy. Drug Alcohol Rev 2014;34:495-8.

42. Van C, Krass I, Mitchell B. General practitioner perceptions of extended pharmacy services and modes of collaboration with pharmacists. J Pharm Pract Res 2007;37:182-6.

43. Bajramovic J, Emmerton L, Tett SE. Perceptions around concordance--focus groups and semi-structured interviews conducted with consumers, pharmacists and general practitioners. Health Expect 2004;7:221-34.

44. Snell L, White L. An exploratory study of the role of emotional intelligence and self-efficacy on service quality and adherence in a weight loss setting. Serv Mark Q 2011;32:228-46.

45. Shoukry G, Wong K, Bartlett D, et al. Treatment experience of people with obstructive sleep apnoea seeking continuous positive airways pressure device provision through community pharmacies: a role for pharmacists? Int J Pharm Pract 2011;19:318-27.

46. Mey A, Knox K, Kelly F, et al. Trust and safe spaces: mental health consumers' and carers' relationships with community pharmacy staff. Patient 2013;6:281-9.

47. White L, Klinner C. Medicine use of elderly Chinese and Vietnamese immigrants and attitudes to home medicines review. Aust $J$ Prim Health 2012;18:50-5.

48. Van C, Mitchell B, Krass I. General practitioner-pharmacist interactions in professional pharmacy services. $J$ Interprof Care 2011;25:366-72.
49. Cheong LH, Armour CL, Bosnic-Anticevich SZ. Multidisciplinary collaboration in primary care: through the eyes of patients. Aust $J$ Prim Health 2013;19:190-7.

50. Dey RM, de Vries MJ, Bosnic-Anticevich S. Collaboration in chronic care: unpacking the relationship of pharmacists and general medical practitioners in primary care. Int J Pharm Pract 2011;19:21-9.

51. Carter SR, Moles R, White L, et al. Exploring patients' motivation to participate in Australia's Home Medicines Review program. Int J Clin Pharm 2012;34:658-66.

52. Clark A, Gilbert A, Rao D, et al. 'Excuse me, do any of you ladies speak English?' Perspectives of refugee women living in South Australia: barriers to accessing primary health care and achieving the Quality Use of Medicines. Aust J Prim Health 2014;20:92-7.

53. Chong WW, Aslani P, Chen TF. Multiple perspectives on shared decision-making and interprofessional collaboration in mental healthcare. J Interprof Care 2013;27:223-30.

54. McMillan SS, Emmerton L. Nurse practitioners: an insight into their integration into Australian community pharmacies. Res Social Adm Pharm 2013;9:975-80.

55. Roberts AS, Benrimoj SI, Chen TF, et al. Understanding practice change in community pharmacy: a qualitative study in Australia. Res Social Adm Pharm 2005;1:546-64.

56. Roberts AS, Benrimoj SI, Chen TF, et al. Practice change in community pharmacy: quantification of facilitators. Ann Pharmacother 2008;42:861-8.

57. Alonso-Perales MDM, Lasheras B, Beitia G, et al. Barriers to promote cardiovascular health in community pharmacies: a systematic review. Health Promot Int 2017;32:535-48.

58. Lowres N, Krass I, Neubeck L, et al. Atrial fibrillation screening in pharmacies using an iPhone ECG: a qualitative review of implementation. Int J Clin Pharm 2015;37:1111-20.

59. Hughes CM, Cadogan CA, Ryan CA. Development of a pharmacy practice intervention: lessons from the literature. Int J Clin Pharm 2016;38:601-6.

60. McKenzie JF, Neiger BL, Planning TR. implementing, and evaluating health promotion programs: a primer. 6th ed: San Francisco, CA: Pearson - Benjamin Cummings, 2013.

61. Franco-Trigo L, Hossain LN, Durks D, et al. Stakeholder analysis for the development of a community pharmacy service aimed at preventing cardiovascular disease. Res Social Adm Pharm $2017 ; 13$

62. Sabater-Hernández D, Moullin JC, Hossain LN, et al. Intervention mapping for developing pharmacy-based services and health programs: A theoretical approach. Am J Health Syst Pharm 2016;73:156-64.

63. Krause J, Van Lieshout J, Klomp R, et al. Identifying determinants of care for tailoring implementation in chronic diseases: an evaluation of different methods. Implement Sci 2014;9:102.

64. Michie S, van Stralen MM, West R. The behaviour change wheel: a new method for characterising and designing behaviour change interventions. Implement Sci 2011;6:42.

65. Durks D, Fernandez-Llimos F, Hossain LN, et al. Use of Intervention Mapping to enhance healthcare professional practice: a systematic review. Health Educ Behav Forthcoming 2017.

66. McMillan SS, King M, Tully MP. How to use the nominal group and Delphi techniques. Int J Clin Pharm 2016;38:655-62.

67. Saba M, Dan E, Bittoun R, et al. Asthma and smoking--healthcare needs and preferences of adults with asthma who smoke. J Asthma 2014;51:934-42.

68. O'Connor M, Fisher C, French L, et al. Exploring the community pharmacist's role in palliative care: focusing on the person not just the prescription. Patient Educ Couns 2011;83:458-64.

69. Swain L, Barclay L. They've given me that many tablets, I'm bushed. I don't know where I'm going: Aboriginal and Torres Strait Islander peoples' experiences with medicines. Aust $J$ Rural Health 2013;21:216-9.

70. Du Pasquier S, Aslani P. Concordance-based adherence support service delivery: consumer perspectives. Pharm World Sci 2008;30:846-53. 
Correction: Qualitative meta-synthesis of barriers and facilitators that influence the implementation of community pharmacy services: perspectives of patients, nurses and general medical practitioners

Hossain LN, Fernandez-Llimos F, Luckett T, et al. Qualitative meta-synthesis of barriers and facilitators that influence the implementation of community pharmacy services: perspectives of patients, nurses and general medical practitioners. BMJ Open 2017;7:e015471. doi: 10.1136/bmjopen-2016-015471

In figure 1, the number below 'Records after duplicates removed' should be 243 not 278. The corrected figure is shown below.

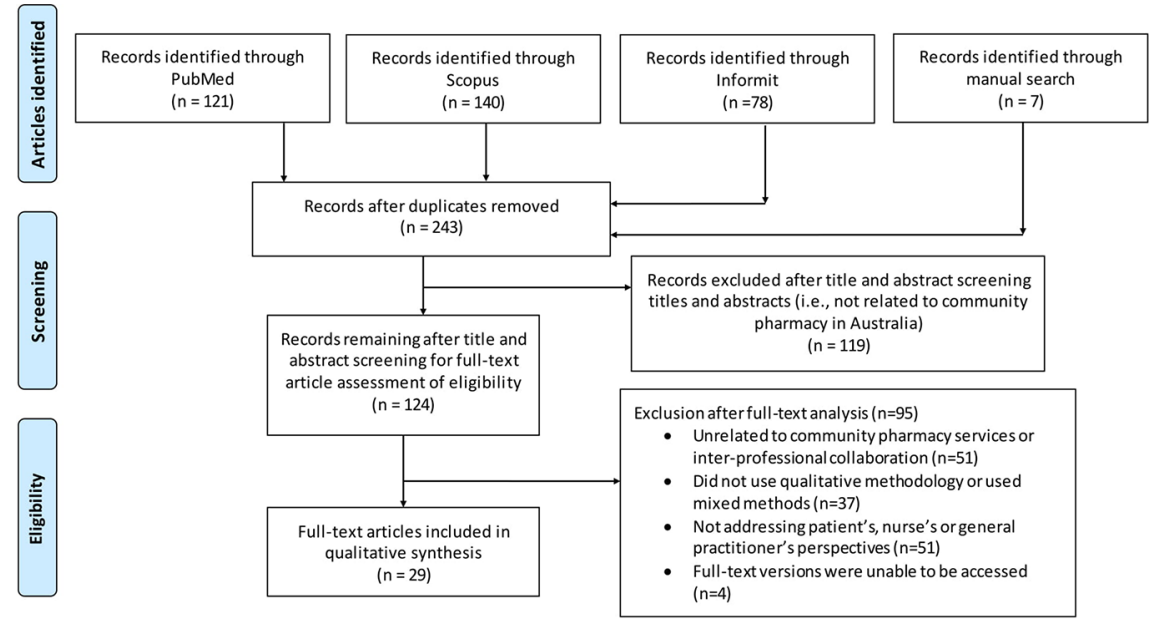

Open Access This is an Open Access article distributed in accordance with the Creative Commons Attribution Non Commercial (CC BY-NC 4.0) license, which permits others to distribute, remix, adapt, build upon this work non-commercially, and license their derivative works on different terms, provided the original work is properly cited and the use is non-commercial. See: http://creativecommons.org/licenses/by-nc/4.0/

C Article author(s) (or their employer(s) unless otherwise stated in the text of the article) 2018. All rights reserved. No commercial use is permitted unless otherwise expressly granted.

BMJ Open 2018;8:e015471corr1. doi:10.1136/bmjopen-2016-015471corr1

Check for updates 